\title{
INTRAPARTUM COMPLICATIONS OF MACROSOMIC FETUS
}

\author{
Razia Iftikhar
}

\begin{abstract}
OBJECTIVE: To study the intrapartum complications of macrosomic fetus. DESIGN: Descriptive study.

SETTING: Department of Obstetrics and Gynaecology at Jinnah Medical \& Dental College and Hospital Karachi, Pakistan from April 2003 to December 2004.

METHODS: One hundred patients were selected for the study. Age, parity, past obstetric performance and estimated fetal weight by ultrasound were noted. Gestational age at delivery was calculated by date of last menstrual period as well as by early scan if available.

RESULTS: Out of 100 patients, 30 cases with intrapartum complications fulfilled the criteria of macrosomia. Among them, 18 had perineal trauma and postpartum haemorrhage, 3 had shoulder dystocia and 9 patients delivered by caesarean section.

CONCLUSION: Macrosomic pregnancy is associated with increased incidence of operative vaginal delivery, postpartum haemorrhage and shoulder dystocia. Prevention requires early detection of risk factor and planning for safe delivery.
\end{abstract}

KEY WORDS: Macrosomia. Caesarean section. Shoulder dystocia. Post Partum Haemorrhage.

\section{INTRODUCTION}

Large for gestational age (LGA) is defined as the fetal weight above the $90^{\text {th }}$ percentile of weight for any specific gestational age or an estimated fetal weight greater than or equal to $4000 \mathrm{gm}^{1}$. Factors predisposing to LGA pregnancy are diabetes (gestational, chemical or insulin dependent), obesity, post datism, multiparity, advance maternal age, previous LGA infant and large stature. Fetal factors include genetic or congenital disorders. Maternal obesity is associated with three to four fold increased likelihood of fetal macrosomia. Prolonged pregnancy results in macrosomic fetus presumably due to continued delivery of nutrients and oxygen to the fetus. Some congenital syndrome in fetus may also be associated with LGA infants. Male fetuses are more likely to be considered LGA because male fetuses are an average of $150 \mathrm{gm}$ heavier than matched female fetuses at each gestational age. ${ }^{1,2}$ The purpose of this study was to focus on the intrapartum complications of macrosomic fetus and their prevention by detecting risk factors and planning for safe delivery.

\section{PATIENTS AND METHODS}

This study was conducted from April 2003 to December 2004 at Jinnah Medical College \& Hospital Karachi. A total number of 100 patients was selected for the study. Inclusion criteria were single fetus, gestational diabetes, post datism, obesity and constitutionally large fetus. All cases with history of previous Caesarean section, short maternal stature, maternal age above 45 years and other medical disorders than diabetes complicating pregnancy were excluded from the study. In all patients, detailed history including age, parity and past obstetric history were noted. A thorough general physical and abdominal examination was carried out. Routine investigations including complete blood picture, urine analysis, blood sugar and ultrasound for gestational age and estimated fetal weight were also carried out. A check was also kept on maternal weight gain particularly among obese patients. All findings were noted on proforma sheet. Those who exceeded 40 weeks of gestation were thoroughly investigated for correct gestational age by menstrual history, ultrasound in early pregnancy and per abdominal examination. Details of labour and complications were documented and analysed. Any normal singleton baby delivered at term that weighed 4000 grams or more was classed as macrosomic. Labour lasting more than 12 hours was defind as prolonged labour and obstetrics intervention was defined as elective or emergency caesarean section, induced labour, forceps delivery or vacum extraction. PPH was defined as estimated blood loss over $500 \mathrm{mls}$ as determined by the attending doctor. Cases of shoulder 
dystocia were identified and treated by senior Obstetrician by Mc Roberts maneuver. All patients with fetuses greater than $3.5 \mathrm{~kg}$ were counselled against the risk of caesarean section. The analysis was performed by using SPSS version 10.0. Frequency and percentages were computed for presentation of all categorical variables.

\section{RESULTS}

Out of 100 patients, there were 30 primigravid patients with age ranging between $20-30$ years and 70 multigravid patients with age between $30-44$ years. Gestational diabetes was found in $30 \%$ of cases, postdatism in $20 \%$, constitutionaly large and fetuses of obese mothers were $25 \%$ each. The average birth weight of infants in majority of the cases (70\%) was 3500-3900 gms as shown in Table I. While infants weighing between 4000- 5000 gms were $30 \%$ who fulfilled the criteria of macrosomia. Maternal weight gain during pregnancy ranged between $15-20 \mathrm{kgs}$ and $75 \%$ of the patients delivered at term while $15 \%$ and $10 \%$ of patients delivered at 41 and 42 weeks of gestation respectively as shown in Table II. Spontaneous vaginal delivery resulted in $50 \%$ of cases, instrumental vaginal delivery in $20 \%$ while caesarean section due to relative cephalopelvic disproportion, fetal distress and non progress of labour was done in 30\% of the cases as shown in Table III. Complications like shoulder dystocia was seen in $3(10 \%)$ cases, perineal trauma and postpartum haemorrhage in 60\% and caeserean section due to non progress of labour and fetal distress in $30 \%$ of the cases Table IV.

TABLE I:

AVERAGE BIRTH WEIGHT OF INFANTS $(n=100)$

\begin{tabular}{|c|c|c|}
\hline WEIGHT & $\begin{array}{c}\text { NO. OF } \\
\text { INFANTS }\end{array}$ & PERCENTAGE \\
\hline $3500-3900 \mathrm{gm}$ & 70 & 70 \\
\hline $4000-4500 \mathrm{gm}$ & 20 & 20 \\
\hline $4500-5000 \mathrm{gm}$ & 10 & 10 \\
\hline
\end{tabular}

TABLE II:

GESTATIONAL AGE AT DELIVERY $(n=100)$

\begin{tabular}{|c|c|c|}
\hline No. of Patients & $\begin{array}{c}\text { Gestation age at } \\
\text { delivery }\end{array}$ & Percentage \\
\hline 75 & $37-40$ weeks & 75 \\
\hline 15 & 41 weeks & 15 \\
\hline 10 & $\geq 42$ weeks & 10 \\
\hline
\end{tabular}

TABLE III:

MODE OF DELIVERY $(n=100)$

\begin{tabular}{|l|c|c|}
\hline \multicolumn{1}{|c|}{ Type } & Number & Percentage \\
\hline Spontaneous vaginal delivery & 50 & 50 \\
\hline Instrumental vaginal delivery & 20 & 20 \\
\hline Abdominal delivery & 30 & 30 \\
\hline
\end{tabular}

TABLE IV:

INTRAPARTUM COMPLICATIONS $(n=30)$

\begin{tabular}{|l|c|c|}
\hline \multicolumn{1}{|c|}{ Complication } & No. of Patients & Percentage \\
\hline $\begin{array}{l}\text { Perineal trauma and } \\
\text { postpartum } \\
\text { haemorrhage }\end{array}$ & 18 & 60 \\
\hline Caesarean section & 9 & 30 \\
\hline Shoulder dystocia & 3 & 10 \\
\hline
\end{tabular}

\section{DISCUSSION}

Macrosomia is defined as either fetal weight greater than the $90^{\text {th }}$ percentile for gestational age, or as weight greater than $4000 \mathrm{gms}^{1}$. At 40 weeks gestation, the $50^{\text {th }}$ persentile for growth is 3,619 grams and $90^{\text {th }}$ percentile is $4234 \mathrm{gm}$. The risk characteristics that increase the probability of the delivery of a macrosomic infant include maternal obesity, multiparity, previous macrosomia infant, maternal diabetes mellitus, postdatism, pre pregnancy weight / height, body mass index, advanced maternal age etc. ${ }^{1}$ Macrosomic infants are at elevated risk of shoulder dytocia, brachial plexus injury, skeletal injuries, muconium aspiration, perinatal asphyxia, hypoglycemia and fetal death ${ }^{2}$. Maternal complications are related to cephalopelvic disproportion and include prolonged labour, labour augmentation, caesarean section, postpartum hemorrhage, infection, thromboembolic events and anaesthesia events. Due to maternal and infant complications, there are different opinions regarding management, and decisions are often made intrapartum due to difficulty in predicting macrosomia ${ }^{3}$. Ultrasound is helpful with a margin of error of $10-15 \%$. This would be of value if performed after 38 weeks of gestation. This is because normal fetal growth is linear where as macrosomic fetus has accelerated growth toward term $^{3}$. We believe that caesarean delivery is justified in all cases of fetal weight estimation greater than $4500 \mathrm{gm}^{4}$. The rate of caesarean section significantly increased among the patients who delivered after labour induction as compared to those whom labour was not induced ${ }^{5}$. More fetuses of diabetic mothers face increased injury at the time of vaginal birth. Cae- 
sarean section offer the promise of avoiding trauma to the fetus but can result in increased morbidity in the mother ${ }^{6}$. The safest mode of delivery is controversial with some evidence pointing to elective caesarean section ${ }^{7}$. A fetus was found to be at significantly increased risk for birth weight greater than 4000 gms, when the estimated fetal weight based on abdominal circumference rather than based on head circumference or femur length ${ }^{8,9}$. Measurment of soft tissue is also not superior to clinical or sonographic prediction in identifying fetus with weight of at least $4000 \mathrm{gm}^{10}$. Common indication for caesarean section in this study was non progress of labour and cephalopelvic disproportion. Parity was also found to be associated strongly with macrosomia. Elective labour induction at or near term has been proposed to present the maternal and perinatal complications of macrosomia. A study conducted by Molaud in Iran states that total caesarean rate in macrosomia was $22.5 \%$ where as it is $30 \%$ in our study. Another study by an American family physician comparing the outcome of patients in whom macrosomia was suspected before delivery to whom it was not ,the author found that the risk of caesaran section was substantially higher (52 versus 30 ) in pregnancies in which macrosomia was suspect$\mathrm{ed}^{11,22}$. One of the purpose of this reseach is making decisions about the method of macrosomia infant child birth. The reason for selecting caesarean is to prevent resulted complications. Spellacy and Berard have mentioned the amount of caesarean section 33.8\% and instrumental delivery $36 \%$. The findings of this study are in general agreement with the numerous other that have formed macrosomia associated with maternal and neonatal morbidity. Physicians caring for pregnant women are confronted with a management dilemma when faced with the women at term carrying what is thought to be an unusually large fetus. Difficulties are encountered when one consider the inaccuracy in our antenatal estimation of fetal weight but there are limitations of this technology, $2 / 3^{\text {rd }}$ of the time ultrasound estimates at best are with in $10 \%$ of actual fetal weight. This means that in order to be $80 \%$ sure that the actual fetal weight is over 4500 grams the ultrasound fetal weight must be 5000 $\mathrm{gm}$. It should be accepted that an experienced examiner is about as accurate as ultrasound at estimating fetal weight. Many different estimates of risk of brachial plexus injuries in the face of shoulder dystocia are reported in literature with an average of approximately $15 \%$. The majority of these injuries recover completely but about $20 \%$ have some permenant sequelae. Therefore, $3 \%$ of all cases of shoulder dystocia suffer some permanent brachial plexus injury. Many clinicians choose to offer a ceasarean section with infants of diabetec moth- ers weighing 4200 gms and non diabetics at 4500 gms. In summary, macrosomia remains a significant clinical problem and no single management plan will be correct for all patients and physicians must indivisualize their clinical judgement. One must be prepared for complications such as shoulder dystocia as they can occur at any delivery. In some clinical situations awaiting spontaneous labour, induction of labour or caesarean section all may be reasonable management plans for the mother with a suspected macrosomic fetus. The incidence of caesarean section was three times more common in the study by OA Adesina ${ }^{12,13}$, the prevalence of caesarean section in the study group was $40.5 \%$ which is because of the liberal use of caesarean delivery as a mode of delivery. Other workers, however, failed to find a substantial decrease in fetal morbidity and mortality in macrosomic babies delivered by caesarean section to justify the high prevalence of caesarean section, and therefore advocate earlier induction at term in mothers of macrosomic babies $^{14,15,16}$. The three major strategies used to detect macrosomia are clinical risk factors, clinicians estimation and ultrasonography with substantial limitation in each. The high risk group triad included obesity, diabetes, and post datism as seen in our study and so in the study group by WN Spellacy ${ }^{17}$. Women at risk should be screened for macrosomic infants, and if found they should be delivered electively by caesarean section. Elective labour induction, at or near term, has been proposed to prevent the maternal and perinatal complications of macrosomia. This intervention has been justified based on anticipated ongoing fetal growth ${ }^{18-20}$. The amount of perineal trauma and postpartum haemorrhage is $60 \%$ which is much higher as compared to $5 \%$ by Kimberly and $4.2 \%$ by Meshari. Inspite of limitations in this study like ultrasound estimation of fetal weight, pre pregnancy weight of patients and estimation of blood loss at the time of delivery, it is concluded that caesarean section is the best mode of delivery in order to prevent intrapartum complications of macrosomic fetus. ${ }^{21,22}$

\section{CONCLUSION}

Macrosomia remains a common cause of intrapartum complication of pregnancy. Its prediction is imperfect. Clinical risk factors, clinical weight estimation and ultrasonography all have limitation in accuracy. There is increased incidence of shoulder dystocia and postpartum haemorrhage. Prevention require early detection of risk factors and planning for safe delivery.

\section{REFERENCES}

1. Boulet SL, Alexander GR. Macrosomic birth in United States. Determinants, out comes, and Pro- 
posed Grades of risk. Am J Obstet Gynecol. 2003; 188:1372 - 1378.

2. Howlim J, Chongtan B, Essa A. Delivery of macrosomic babies. Management and outcomes of 330 cases. J Obstet. Gynaecol. 2002; 22: 370 - 374.

3. Rhodes JC, Kenneth C. Contribution of excess weight gain during pregnancy and macrosomia to the caesarean delivery rate. $\mathrm{Br} \mathrm{J}$ Obstet Gynecol. 2003;111: 1181 - 1185.

4. Kraiem J, Chiha N, Bouden S. The delivery of macrosomic infants weighting $4500 \mathrm{~g}$ and more. A report of 61 cases, Tunis Med J. 2004;82:256 61.

5. Simhayoff N, Sheiner E, Lavy A. To induce or not to induce labor: a macrosomic dilemma.J Gynecol Obstet. 2004;58(3):121 - 5 .

6. Conway DL. Choosing route of delivery for the macrosomic infant of a diabetic mother: caesarean section versus vaginal delivery. J Mat Fetal Neonatal Med.2002;12(6):442 - 8.

7. Mulik V, Usha kiran TS, Bethal J. The outcome of macrosomic fetuses in a low risk primigravid population. Int J Gynaecol Obstet. 2003; 80(1):15 $-22$.

8. Ruplinger J, Marquardt DN. Should induction of labor be considered in a woman with a macrosomic baby? J Fam Pract. 2001;50(9):745 - 8.

9. Sokol RJ, Chik L, Dombrowski MP. Correctly identifying the macrosomic fetus: improving ultrasonography based prediction. Am J Obstet Gynecol. 2000; 182(6):1489 - 95.

10. Chauhan SP, West DJ, Scardo JA. Antepartum detection of macrosomic fetus: Clinical versus sonographic including soft tissue mearurment.J Obstet Gynecol. 2000;95(5):639- 42.

11. Orskou J, Kesmode U, Henriksen TB. An increasing proportion of infants weigh more than 4000 grams at birth. Acta Obstet Gynecol Scand. 2001; 80:931 - 936 .

12. O, A. Adesina and O, Olayemi. Fetal macrosomia at the University College Hospital, Ibadan: a 3 year review. J Obstet Gynaecol 2003;23: 30 - 33.

13. Campbell S, Westerway, Keogh J, Heard R. Incidence of fetal macrosomia and birth complications in Chinese Immigrant women. Aust $\mathrm{N} \mathrm{Z} \mathrm{J} \mathrm{Obstet-}$ rics Gynecol. 2003;43:46 - 49.

14. Boyd SL. Fetal macrosomia in progress. In Obstetrics and Gynaecology, Vol.4, edited by Stud J. Edinburgh, Churchill Living Stone. Chapter 8, Pp. 126.

15. Bryant, Leonard, Land Wehr JB. Limited usefulness of fetal weight in predicting neonatal brachial plexus injury. Am J Obstet Gynecol. 1998; 179: $686-9$.

16. Lebanoff K, Mills JL, Berendes HW. Mothers birth weight as a predictor of macrosomia. Am J Obstet Gynecol. 1985; 153:253 - 7.

17. Spellacy WN, Miller S, Winger. A macrosomia maternal characteristics and infant complications. J Obstet Gynaecol. 1985;16(2):158-161.

18. Abrams BF, Laros RKJ. Pre pregnancy weight gain and birth weight. Am J Obstet Gynecol. 1986;154:503-9.

19. Sanchez - Ramos L, Berstein S and Kaunitz AM. Expected management versus labour induction for suspected fetal macrosomia: A systematic review. J Obstet Gynaecol. 2002;100:997 - 1002.

20. Rouse DJ, Owen J, Goldenberg RL. The effectiveness and cost of elective caesarean section delivery for fetal macrosomia diagnosed by ultrasound. JAMA. 1996;276: 1480 - 6.

21. Weeks JW, Petman T, Spinnato JA. Fetal macrosomia: does antenatal prediction affect delivery route and outcome?. Am J Obstet Gynecol. 1995; 173:1215 - 9 .

22. Zamorski MA. Management of suspected fetal macrosomia. J Am Family Physician. 2001; 63:2026.

\begin{tabular}{l|} 
AUTHOR AFFILIATION: \\
Dr. Razia Iftikhar \\
Associate Professor \\
Department of Obstetrics \& Gynaecology \\
Baqai Medical University \\
Karachi, Sindh - Pakistan. \\
E-mail: rrg786@yahoo.com
\end{tabular}

